\title{
How Respected Family Physicians Manage Difficult Patient Encounters
}

\author{
Nancy Elder, MD, MSPH, Rick Ricer, MD, and Barbara Tobias, MD
}

Background: Nearly all family physicians have patients that engender a sense of frustration or dislike, often described as "difficult." Most research in this area focuses on describing these patients and their physicians, not management or coping.

Objective: To describe how respected family physicians identify, manage, and cope with difficult patient encounters.

Methods: Qualitative semi-structured interview study. Participant physicians described as "excellent" were recommended by medical school family medicine faculty around the county. Interview questions included "describe the patient you least like seeing," and "how do you keep sane but still assure adequate care for the patient?" Interviews were analyzed using the editing method, looking for common categories and themes.

Results: 102 physicians were interviewed. Physicians described both patient behaviors (stay sick and demanding) as well as medical problems (multiple, chronic pain, drug seeking, psychiatric) that they found frustrating. Difficult encounters occurred when these patient behaviors and medical problems clashed with physicians' personal and practice traits. Their management strategies to return the encounter to success incorporated collaboration, appropriate use of power and empathy.

Conclusions: We propose a model where clashes between patient behaviors and physicians' traits turn a successful encounter of collaboration, appropriate use of power and empathy into a difficult encounter of opposition, misuse of power and compassion fatigue. Management strategies used by our participants aim to return success to the encounter and may serve as a guide for practicing physicians and for future research. (J Am Board Fam Med 2006;19:533-41.)

For a quarter of a century, the medical literature has acknowledged that there are patients in whom a "heartsink" feeling occurs when their names show up on a physicians' schedule. ${ }^{1,2}$ Both anecdotal reports, ${ }^{3,4}$ and studies of physicians ${ }^{1,5}$ and these patients $^{6-8}$ have been published. Common to the definition of these patients is "the distress they cause their doctor and the practice." 1

A number of studies have attempted to discover why these patients cause such distress to physicians. A complex and daunting literature has arisen, looking at physician variables such as workload, job

This article was externally peer-reviewed.

Submitted 9 December 2005; revised 20 March 2006; accepted 28 March 2006.

From the Department of Family Medicine, University of Cincinnati, Cincinnati, $\mathrm{OH}$.

Conflict of interest: none declared.

Corresponding author: Nancy C. Elder, MD, MSPH, Department of Family Medicine, University of Cincinnati, PO Box 670582, Cincinnati, OH 45267-0582 (E-mail: eldernc@fammed.uc.edu). satisfaction, and psychosocial attitudes, ${ }^{1,6}$ Freudian countertransference, ${ }^{9}$ patients' medical problems, ${ }^{6-8,10-12}$ and patient demographics. ${ }^{6,8}$ From these, causation models have been developed that generally contain three or four interacting components: patient characteristics, physician characteristics, the environment and relationship skills. ${ }^{13-15}$

Studies examining physician characteristics have found that physicians with lower job satisfaction, ${ }^{1}$ less experience, ${ }^{7}$ and poorer psychosocial attitudes ${ }^{6}$ describe more difficult patient encounters. Fewer studies have studied how physicians actually manage difficult patients. ${ }^{14}$ Instead, management advice is given anecdotally $3,4,16$ or from an educational or psychological perspective. $^{13,15,17}$

Despite all this advice, practicing physicians lack a "best practices" method of managing difficult patient encounters. A first step in developing a "best practice" is to develop a conceptual model, based on input from stakeholders, such as physicians. ${ }^{18}$ Often, input from "expert" or "excellent" 
physicians serves as a starting place to begin this research. ${ }^{19,20}$ Respected family physicians can certainly serve as these stakeholders, and by sharing their expertise and experience, help clarify approaches to these difficult encounters.

We elected to choose practicing physicians who serve as volunteer preceptors for medical students in family medicine and described as excellent by predoctoral directors of family medicine. These physicians elect to be under constant scrutiny by students and fellow physicians. Predoctoral directors of family medicine and other faculty members receive constant feedback not just on these physicians' ability to teach, but on the quality of their medical care, as well. These preceptors are visited and observed by faculty members on an ongoing basis. The purpose of this paper is to elicit descriptions of difficult patients and their management from these respected family physicians and to develop a model to first, assist physicians in understanding and improving their difficult patient encounters and second, serve as a basis for future research to confirm the best practices for caring for such patients.

\section{Methods \\ Participants}

Based on known initial contacts, one author (RR) contacted predoctoral directors and family medicine faculty members at 15 medical schools across the United States. These schools were chosen for convenience and geographic diversity. They, in turn, recommended excellent preceptors and assisted with interview logistics. Only 3 of the 105 recommended physicians could not be interviewed due to scheduling problems. "Excellence" was described to the faculty members as being experienced (at least 10 years in practice), up to date, competent, received the highest ratings from learners and enjoyed both teaching and practice. This study received approval from our institutional review board.

\section{Data Collection}

As part of a larger in-person interview study capturing the experience and wisdom of respected and experienced family physicians, questions on managing difficult and unlikable patients were asked in a semi-structured interview format. Based on the medical literature, we described these difficult pa- tients as "the type of patient you least like to see, that kind that make you cringe when you see them on your schedule." ${ }^{\prime, 4}$ Physicians were asked to describe or give examples of patients that fit this definition, and to tell "what do you do to keep yourself sane, but still assure adequate care for the patient?" Since this topic was only one of several asked of the participants, saturation for this specific area was not the deciding factor for the number of interviews performed. However, during the last phase of interviewing, few new ideas were being introduced by the participants. One author (RR) an experienced family physician, performed all the interviews. All but six interviews were audiotaped, but due to technical difficulties, 4 additional tapings were unsuccessful. Extensive notes were made during and after each interview, augmented by RR reviewing the audiotapes. Due to financial constraints, not all tapes were transcribed, but were listened to several times, and selected quotes were transcribed.

\section{Data Analysis}

Two authors (RR and NE) each independently coded all the notes into categories of problem patients and management strategies and then met to discuss the existing and potential categories and themes. Then using the editing method, ${ }^{21,22}$ one author (NE, an experienced family physician and qualitative researcher) re-coded all the notes and quotes using NVivo 2.0 software, beginning with the consensus categories developed during the initial coding. She sorted the interview data into further coding categories derived from the data, explicitly checking them against other categories and the original data, and searching for patterns and themes. Then, during a series of discussions, a third family physician (BT) joined the analysis team to provide an outside check. We all practice in different settings, and we believe our diversity of experience added to the "trustworthiness" of our analysis. ${ }^{23,24} \mathrm{We}$ reviewed and discussed the original notes and quotes, as well as the coded comments, coding categories, and the medical literature, looking for themes and models of interactions between patient behaviors, management strategies, reasons for perceiving an encounter as difficult and physicians' emotional responses. 
Table 1. Participant Characteristics

\begin{tabular}{lr}
\hline Total number of participants & 102 \\
States represented: & 15 \\
(CA, CO, GA, KY, MO, NE, OK, OH, OR, & \\
SC, TN, TX, VT, VA, WI) & \\
Practice location & 29 \\
$\quad$ Urban & 57 \\
Suburban & 16 \\
Rural & \\
Gender & 75 \\
Male & 27 \\
Female & \\
Ethnicity & 92 \\
White & 2 \\
Asian & 4 \\
Hispanic & 3 \\
African American & 1 \\
Native American & \\
Age & $35-85$ \\
Range & 49 \\
Mean &
\end{tabular}

\section{Results}

The majority of the participant physicians were male $(75 \%)$ with an average age of 49 (Table 1). This compares with a population that is $68 \%$ male and an average age of 45 for American Academy of Family Physician members. (〈www.AAFP.org $\rangle$ ) Fifteen states in all regions of the United States were represented, and the vast majority of participants were white. Only one participant claimed that he never had a difficult patient, the remaining participants related stories of one or more types of patients they found unlikable or difficult.

We focused our analysis on four areas: the types of interactions participants found difficult, management and coping strategies for caring for these patients, reasons these encounters were perceived as difficult, and physicians' emotional responses.

\section{Types of Difficult Patients}

Our participants described patient behaviors as well as medical problems they found difficult. Patient behaviors included "stay sick," demanding, and other behaviors (Table 2). Stay sick behaviors included those patients who were perceived as both the worried well and social visits, as well as those who were noncompliant or ignored problems. For example, this 46-year-old white female physician describes a difficult patient as, "The patient who won't get better or change. They seem to need their illness or complaints." Demanding behaviors were also frequently disliked by physicians, as described by this 39-year-old white male physician, "the noncompliant, non-appreciative entitled demanders." Other behaviors, including whining and lack of focus, were also mentioned. A 36-year-old white male physician described such a patient, with a personal reference, "A patient who reminds me of my mom, who won't answer questions, but goes somewhere unrelated and stays away from the reason they come in to prolong the visit... It's the worst use of time in the office. You can't figure out the reason they're here."

Multiple medical complaints led the list of difficult patient medical problems, followed by chronic pain, drug seeking, and psychiatric problems. Multiple medical problems were usually seen as difficult when combined with difficult patient behaviors. For example, from a 55-year-old white male physician, "the somatisizing never satisfied patient with multiple complaints and expectations that are never met." Drug seeking and chronic pain issues were difficult for physicians because of their overlap, for example, from a 40-year-old white male physician, "The chronic pain patient who wants more narcotics. I don't know if they need it or not. I want to do the right thing, but it's hard to know if I'm helping or hurting." Psychiatric illnesses were occasionally mentioned, with patients with borderline personalities as the most common of these.

\section{Management and Coping Strategies}

The physician participants discussed management strategies that we classified into three categories: collaboration, empathy, and the appropriate use of power. In addition, there was a set of strategies related to terminating relationships, when all else had failed (Table 3). These strategies were designed to achieve multiple goals for the physician, including providing quality patient care, producing clinical income, achieving efficient office flow and maintaining physician well being. Collaboration with the patient included priority setting, the performance of diagnostic skills, decision making abilities, the use of teamwork and coaching. These skills were often used together as seen in this quote by a 43-year-old white female physician, "I usually do a lot of patient education with them and encourage them to start taking responsibility and adjusting their expectations of what we can accomplish, and try to encourage them to think of their care as a 
Table 2. Types of Difficult Patients Described by Physician Participants $(\mathbf{N}=101)$ *

\begin{tabular}{|c|c|c|c|}
\hline Main Type of Problem & Category of Patient Descriptors & Examples of Descriptors & Frequency of Mentions \\
\hline \multirow[t]{15}{*}{ Behavior problems } & \multirow[t]{6}{*}{ Stay sick behaviors } & Worried well & 19 \\
\hline & & Ignoring problems & 4 \\
\hline & & Noncompliant & 4 \\
\hline & & Overly dependent & 4 \\
\hline & & Social visits & 3 \\
\hline & & Abdicates responsibility & 2 \\
\hline & \multirow[t]{2}{*}{ Demanding behaviors } & Demand own care & 19 \\
\hline & & Manipulative & 3 \\
\hline & \multirow[t]{7}{*}{ Other patient behaviors } & Whiner & 7 \\
\hline & & Unfocused & 3 \\
\hline & & ER abuser & 1 \\
\hline & & Family conflict & 1 \\
\hline & & Hidden agenda & 1 \\
\hline & & Excessively complimentary & 1 \\
\hline & & Slow talkers & 1 \\
\hline \multirow[t]{9}{*}{ Medical problems } & Multiple problems & Multiple complaints & 23 \\
\hline & \multirow[t]{2}{*}{ Pain, drug problems } & Drug seeking & 18 \\
\hline & & Chronic pain & 10 \\
\hline & \multirow[t]{3}{*}{ Psychiatric problems } & Borderline personality & 6 \\
\hline & & Substance abuse & 2 \\
\hline & & Bipolar disorder & 1 \\
\hline & \multirow[t]{3}{*}{ Miscellaneous problems } & Difficult diagnoses & 2 \\
\hline & & Workman's compensation & 2 \\
\hline & & Partners' patients & 2 \\
\hline
\end{tabular}

* Participants could mention more than one type of difficult patient.

team effort between them and myself." The appropriate use of power included setting rules of clinical management, as well as setting boundaries and limits. Empathy was important, with emotional understanding and compassion listed as important attributes. Occasionally, physicians found it necessary to terminate the doctor-patient relationship, as this 53-year-old white male admitted, "When all else fails, and I'm very frustrated with the patient, I refuse to give them any narcotics and reverse my doctor-patient relationship skills-they find another doctor."

\section{Reasons for Perceiving the Encounter As Difficult}

As the physicians discussed the type of patients they found difficult and their strategies for management, their reasons for perceiving these encounters as difficult also emerged: clashes with professional identity, personal qualities, time management, comfort with patient autonomy, confidence in skills, and trust in patients (Table 4). Together, these categories comprise traits that can describe individual physicians. When these clash with patient behaviors during an encounter, physicians can experience that "heartsink" feeling. Problems with professional identify were commonly mentioned, because patients' seeming unwillingness to get better conflicted with some physicians' professional standards, as this 49-year-old white male physician commented, "People who don't take responsibility for their own life, they make bad choices and blame external forces-this is the opposite of me and they won't listen or change." Often multiple reasons were combined. For example, this 40-year-old white male noted that difficult patients, "take time, they're clingy, there are no answers, they're unwilling to do what's suggested and they're psychologically draining."

\section{Physicians' Emotional Responses}

Fifty-two of the physicians mentioned that recognizing and dealing with their emotions was an important part of coping. Emotions mentioned included frustration, helplessness, fear, and resent- 
Table 3. Management and Coping Strategies Given by Physician Participants $(\mathrm{N}=101)^{*}$

\begin{tabular}{|c|c|c|c|}
\hline Encounter Component & $\begin{array}{l}\text { Management and Coping } \\
\text { Strategy }\end{array}$ & Examples of Strategy & $\begin{array}{l}\text { Frequency of } \\
\text { Mentions }\end{array}$ \\
\hline \multirow[t]{11}{*}{ Collaboration } & Priority setting & Prioritize patient concerns & 20 \\
\hline & Diagnostic skills & Thorough history, physical and testing & 13 \\
\hline & \multirow[t]{4}{*}{ Decision making } & Explain fully & 13 \\
\hline & & Be consistent and objective & 12 \\
\hline & & Facilitate patient decision making & 12 \\
\hline & & Be honest and fair & 11 \\
\hline & \multirow[t]{3}{*}{ Teamwork } & Use referrals (mental health, pain, etc) & 12 \\
\hline & & Enlist/see family & 2 \\
\hline & & Provide quality care & 1 \\
\hline & \multirow[t]{2}{*}{ Coaching } & Set small, achievable goals & 8 \\
\hline & & Short term symptom relief & 2 \\
\hline \multirow[t]{8}{*}{ Appropriate use of power } & \multirow{4}{*}{$\begin{array}{l}\text { Set clinical management } \\
\text { rules }\end{array}$} & Schedule patient frequently, longer visits & 26 \\
\hline & & Clinic time management & 1 \\
\hline & & Good documentation & 1 \\
\hline & & Allow a tincture of time & 1 \\
\hline & \multirow[t]{4}{*}{ Set boundaries and limits } & Make explicit rules & 19 \\
\hline & & Limit number of patient concerns & 10 \\
\hline & & Set general limits & 9 \\
\hline & & Limit time at each visit & 4 \\
\hline \multirow[t]{5}{*}{ Empathy } & \multirow[t]{5}{*}{ Empathy } & Understand patients psyche and emotions & 9 \\
\hline & & Be compassionate and firm & 8 \\
\hline & & Be patient centered & 1 \\
\hline & & Reinforce positives & 1 \\
\hline & & Keep professional distance & 1 \\
\hline \multicolumn{4}{|l|}{$\begin{array}{l}\text { Consistently unsuccessful } \\
\text { patient encounter }\end{array}$} \\
\hline \multirow{3}{*}{$\begin{array}{l}\text { Opposition, misuse of power, } \\
\text { compassion fatigue }\end{array}$} & \multirow[t]{3}{*}{ Termination } & Dismiss patient, make them want to leave & 11 \\
\hline & & Ignore problems & 1 \\
\hline & & Charge more & 1 \\
\hline
\end{tabular}

* Participants could mention more than one strategy.

ment, but most physicians simply mentioned the importance of being aware of and acknowledging one's own emotions. Physicians mentioned "psyching up" by checking their own attitudes and recog- nizing their own biases, as well as trying to separate their own emotions from those of the patient, remaining open to surprises, and even using breathing exercises. After an encounter, some physicians

Table 4. Reasons for Perceiving the Encounter As Difficult: $(\mathrm{N}=101)^{*}$

\begin{tabular}{llc}
\hline Physician Characteristic & \multicolumn{1}{c}{ Reason Given by Physician } & Frequency of Mentions \\
\hline Professional identity & I am unable to make better & 41 \\
& Conflicts with my professional standards & 21 \\
Personal qualities & Feel taken advantage of & 21 \\
& Difficulty making relationship with patient & 21 \\
Time management & Takes too much time & 24 \\
Comfort with patient autonomy & Patient sets the agenda & 6 \\
Confidence in skills & Too hard to solve & 6 \\
Trust in patient & Lose trust in patient & 5 \\
\hline
\end{tabular}

* Participants could mention more than one reason. 


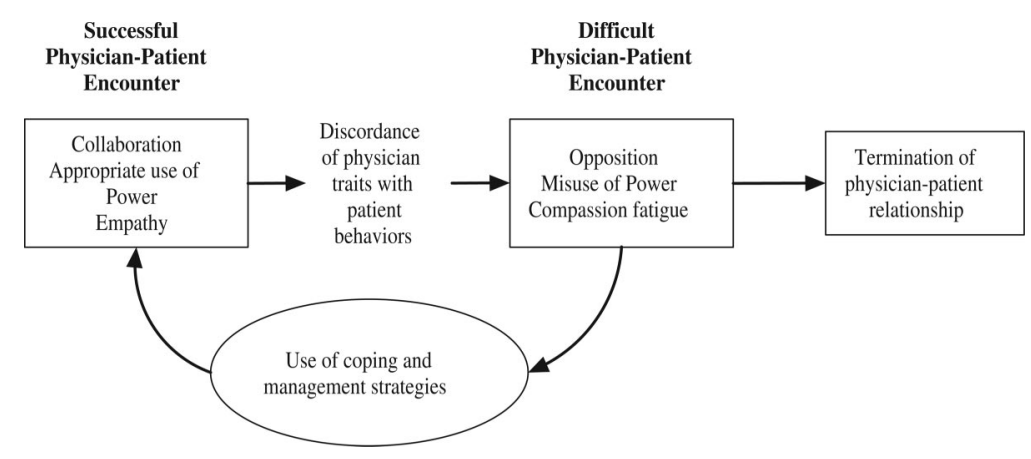

Figure 1. Model of the care cycle for difficult patients as performed by respected family physicians.

mentioned using journaling and reflection, as well as discussion with others, both informally and with Balint support groups as a way of dealing with their emotions.

\section{Discussion}

Of the 102 respected family physicians interviewed, 101 acknowledged that they have patients they find unlikable, difficult, and problematic. This acknowledgment of having difficult patients appears to be an almost universal experience of physicians. Respected physicians strive to practice in a situation that encompasses patient-centered care, but is also financially viable and supportive of staff and physicians. $^{25,26}$ Therefore, many components make up a successful physician-patient encounter, including collaboration, ${ }^{27}$ the appropriate use of power, ${ }^{28}$ and empathy. ${ }^{29-31}$ We propose a model (Figure 1) where clashes between patient behaviors and the traits that are important to physicians can turn a successful relationship into a difficult one defined by opposition, misuse of power (by either physician or patient), and compassion fatigue. Management strategies aim to return the encounter back to success, but when not possible, termination of the physician-patient relationship can and does occur. ${ }^{32}$

There was consistency among our participants in the patients they found difficult: demanding patients who stay sick, unfocused patients with multiple complaints, and patients with chronic pain who may or may not need narcotics. Many of these behaviors and medical problems have been previously described in the literature. ${ }^{6,7,12,15,33-35}$ These patient qualities tend to clash with physician traits that encompass who they are-their professional identity and personal self-worth, their time management skills and confidence, and even their comfort with patient autonomy and trust in the pa- tient. $^{27,36}$ Especially when physicians feel their professional identity or personal self-worth is threatened, they may feel a loss of control. ${ }^{27,37} \mathrm{~A}$ desire to control and to possess mastery is deeply rooted in the physician culture and profession. ${ }^{38}$ Feeling out-of-control certainly leads to the uncomfortable emotions that define a difficult patient encounter and may lead to physician dissatisfaction. ${ }^{27,39,40}$

Collaboration occurs when physicians and patients together work to define problems, pursue investigations and undertake treatment. Both physicians and patients have different needs and desires for this collaboration..$^{31,41-43}$ When physicians and patients have matching styles (both desire shared decision making, for example, or a patient prefers not to make decisions and has a paternalistic leaning physician) then satisfaction is higher for the encounter for both patient and physician. ${ }^{31,42}$ When there is discordance, satisfaction is lower, and can even lead to opposition and a difficult encounter. Several of the difficult patient behaviors challenge physicians' abilities to be cooperative, including ignoring problems, abdicating responsibility and being manipulative. Our physicians describe methods they use to restore collaboration to a difficult encounter, including the prioritizing of concerns, coaching, teamwork, and facilitating decision making. Many techniques are needed, as specific clinical situations will determine which strategy will be most useful.

Power is important in the physician-patient encounter. Both patients and physicians exert power at different levels, although the physician has traditionally been the more powerful member. ${ }^{28,41}$ Patients exert their power by the information they choose to share with the physician, as well as with their decisions to adhere to treatment plans. Phy- 
sicians exert theirs by offering some, but not all, treatment and diagnostic options and controlling the flow of conversation with questions. When patients are perceived by physicians as demanding, noncompliant, or ignoring problems, physicians may see this as an affront to their professional identity (which gives them their power) and may lead to the misuse of power. Again, excellent physicians go to their management strategies, this time to restore the appropriate use of power by managing their clinical schedule and setting limits and boundaries for the encounter. Although these are well established suggestions for dealing with difficult patients, ${ }^{4,14,17}$ they have not been placed within the context of the use of power, which we believe is a helpful way for physicians to frame the problem.

Empathy is a hallmark of the physician-patient relationship. ${ }^{44}$ Caring and understanding are adjectives commonly used by patients to describe an ideal physician. When physicians feel that patients' behaviors confront them personally, such as when patients are manipulative or drug seeking, they may feel like their caring has been in vain, and compassion fatigue can set in. ${ }^{27,45}$ Extending empathy, by focusing on the patient's emotions and being firm but compassionate, are strategies our participants use to return a difficult encounter to success. Our participants also stressed the importance of acknowledging their own emotional responses when caring for these difficult patients. Research has suggested that physicians who are aware of and accept their emotions may improve their emotional intelligence and physician-patient relationships. ${ }^{7,34} \mathrm{Al}-$ though we did not directly ask our participants whether experiencing difficult patient encounters led to burnout, or consideration of leaving clinical practice or early retirement, other research would suggest that dissatisfaction with practice, which is closely tied to physicians' ability to manage their day-to-day patient interactions ${ }^{40}$ may lead to such outcomes. ${ }^{45-47}$ Advice for physicians' self-care includes ideas suggested by our participants, such as Balint or support groups, retreats, and finding a colleague confidante to help alleviate the frustration and conflict. ${ }^{45,48,49}$

Ultimately, physician management strategies may not succeed and the physician-patient relationship may be terminated. Both physicians and patients initiate this event, and our participants described both formal terminations, as well as the more informal "put off" (deliberately refusing to agree to patient's request so the patient will go elsewhere) and "hand off" (deliberately referring elsewhere with the purpose of terminating the relationship). ${ }^{32}$ Few physicians see this as a desirable outcome to a difficult physician-patient encounter, and our participants described using it only when nothing else worked.

This study has several limitations. All the participants were volunteer preceptors. Many excellent physicians who are not preceptors were therefore not included in this sample, and may have given us some new or differing responses. We had a preponderance of male physicians, and they may perceive their interactions with difficult patients differently, as gender does influence the patientdoctor relationship. ${ }^{50}$ Our sample was overwhelmingly white, and our results may not be applicable to physicians of color. However, our participants otherwise came from a variety of geographic locations and community sizes. The definition we used to describe "excellent" included excellent teaching skills, which may have limited some excellent clinicians who were poor teachers (or included excellent teachers who were only average clinicians). However, we believe that medical school faculty generally had a good insight into who were good clinicians as well as good teachers. Physician stories were self-reports and not corroborated by any additional sources. But since the definition of a difficult patient was the emotional response within the physician and the data obtained were the physician's perceptions, we felt it was sufficient to use physician reports alone.

The medical literature has intermittently published studies describing the factors that make up a difficult physician-patient encounter. ${ }^{1-8,24}$ Occasionally articles with advice for managing such patients are published, often lists based on "expert opinion" (or the author's personal experience). ${ }^{3,4,13-17}$ By systematically interviewing respected family physicians, from a variety of geographic and practice situations, we have developed a model of how successful physician-patient encounters turn difficult, and how management strategies based on returning cooperation, the appropriate use of power and empathy to the encounter has assisted these physicians in their practices. Whether the difficult patient management strategies espoused by our participants, or those published in the medical literature, are the "best prac- 
tices" available is unknown. However, we believe our model of how successful encounters become difficult and how they can return to success can serve as a template not only for future research on this important subject but can assist practicing family physicians in better understand their own difficult encounters.

\section{References}

1. Mathers N, Jones N, Hannay D. Heartsink patients: a study of their general practitioners. Br J Gen Pract 1995;45:293-6.

2. Mathers NJ, Gask L. Surviving the 'heartsink' experience. Fam Pract 1995;12:176-83.

3. Christensen GJ. Treating the potential problem patient. J Am Dent Assoc 2001;132:1591-3.

4. Gillette RD. 'Problem patients': a fresh look at an old vexation. Fam Pract Manag 2000;7:57-62.

5. Bellon JA, Fernandez-Asensio ME. Emotional profile of physicians who interview frequent attenders. Patient Educ Couns 2002;48:33-41.

6. Jackson JL, Kroenke K. Difficult patient encounters in the ambulatory clinic: clinical predictors and outcomes. Arch Intern Med 1999;159:1069-75.

7. Crutcher JE, Bass MJ. The difficult patient and the troubled physician. J Fam Pract 1980;11:933-8.

8. John C, Schwenk TL, Roi LD, Cohen M. Medical care and demographic characteristics of 'difficult' patients. J Fam Pract 1987;24:607-10.

9. Groves JE. Taking care of the hateful patient. N Engl J Med 1978;298:883-7.

10. Walker EA, Katon WJ, Keegan D, Gardner G, Sullivan M. Predictors of physician frustration in the care of patients with rheumatological complaints. Gen Hosp Psychiatry 1997;19:315-23.

11. Smucker DR, Zink T, Susman JL, Crabtree BF. A framework for understanding visits by frequent attenders in family practice. J Fam Pract 2001;50:84752.

12. Hahn SR, Kroenke K, Spitzer RL, et al. The difficult patient: prevalence, psychopathology, and functional impairment. J Gen Intern Med 1996;11:1-8.

13. Adams J, Murray R 3rd. The general approach to the difficult patient. Emerg Med Clin North Am 1998; 16:689-700.

14. Haas L, Leiser J, Magill M, Sanyer O. Management of the difficult patient. Am Fam Phys 2005;72: 2063-8.

15. Smith S. Dealing with the difficult patient. Postgrad Med J 1995;71:653-7.

16. Baum NH. 12 tips for dealing with difficult patients. Geriatrics 2002;57:55-7.

17. Lechky O. There are easy ways to deal with difficult patients, MD says. Can Med Assoc J 1992; 146:1793-5.
18. Mold JW, Gregory ME. Best practices research. Fam Med 2003;35:131-4.

19. Irby DM. How attending physicians make instructional decisions when conducting teaching rounds. Acad Med 1992;67:630-8.

20. Roter DL, Larson S, Fischer GS, Arnold RM, Tulsky JA. Experts practice what they preach: A descriptive study of best and normative practices in end-oflife discussions. Arch Intern Med 2000;160:3477-85.

21. Miller M, Crabtree BF. Clinical research. A multimethod typology and qualitative roadmap. In: Crabtree BF, Miller M, editors. Doing Qualitative Research. 2nd ed. Thousand Oaks: Sage; 1999.

22. Miller W, Crabtree BF. Qualitative analysis: how to begin making sense. Fam Pract Res J 1994;14:289_ 97.

23. Crabtree B, Miller W. Doing qualitative research, Second Edition. Thousand Oaks (CA): Sage; 1999.

24. Elder NC, Miller WL. Reading and evaluating qualitative research studies. J Fam Pract 1995;41:279_ 85.

25. Aita V, McIlvain H, Backer E, McVea K, Crabtree B. Patient-centered care and communication in primary care practice: what is involved? Patient Educ Couns 2005;58:296-304.

26. Stewart M, Brown JB, Donner A, et al. The impact of patient-centered care on outcomes. J Fam Pract 2000;49:796-804.

27. Salmon P, Hall GM. Patient empowerment and control: a psychological discourse in the service of medicine. Soc Sci Med 2003;57:1969-80.

28. Goodyear-Smith F, Buetow S. Power issues in the doctor-patient relationship. Health Care Anal 2001; 9:449-62.

29. Mead N, Bower P, Hann M. The impact of general practitioners' patient-centeredness on patients' postconsultation satisfaction and enablement. Soc Sci Med 2002;55:283-99.

30. Stewart MA. Effective physician-patient communication and health outcomes: a review. CMAJ 1995; 152:1423-33.

31. Street RL, Jr., Gordon HS, Ward MM, Krupat E, Kravitz RL. Patient participation in medical consultations: why some patients are more involved than others. Med Care 2005;43:960-9.

32. Stokes T, Dixon-Woods M, McKinley RK. Ending the doctor-patient relationship in general practice: a proposed model. Fam Pract 2004;21:507-14.

33. Hall JA, Roter DL, Milburn MA, Daltroy LH. Patients' health as a predictor of physician and patient behavior in medical visits. A synthesis of four studies. Med Care 1996;34:1205-18.

34. Schwenk TL, Marquez JT, Lefever RD, Cohen M. Physician and patient determinants of difficult physician-patient relationships. J Fam Pract 1989;28: $59-63$. 
35. Schafer S, Nowlis DP. Personality disorders among difficult patients. Arch Fam Med 1998;7:126-9.

36. Braddock CH, 3rd, Snyder L. The doctor will see you shortly. The ethical significance of time for the patient-physician relationship. J Gen Intern Med 2005;20:1057-62.

37. Pendergrast J, Henry J. Reconnecting with the joy of medicine. Fam Pract Manag 2002;9:84.

38. Remen RN, Tarcher JP. The heart of learning: spirituality in education. In: Glazer S, editor. Educating for Mission, Meaning and Compassion. New York: Putnam; 1999.

39. Freeborn DK. Satisfaction, commitment, and psychological well-being among HMO physicians. West J Med 2001;174:13-8.

40. Landon BE, Reschovsky J, Blumenthal D. Changes in career satisfaction among primary care and specialist physicians, 1997-2001. JAMA 2003;289: 442-9.

41. Emanuel EJ, Emanuel LL. Four models of the physician-patient relationship. JAMA 1992;267:2221-6.

42. Jahng KH, Martin LR, Golin CE, DiMatteo MR. Preferences for medical collaboration: patient-physician congruence and patient outcomes. Patient Educ Couns 2005;57:308-14.
43. Street RL, Jr., Krupat E, Bell RA, Kravitz RL, Haidet P. Beliefs about control in the physicianpatient relationship: effect on communication in medical encounters. J Gen Intern Med 2003;18:609_ 16.

44. Epstein RM. The science of patient-centered care. J Fam Pract 2000;49:805-7.

45. Benson J, Magraith K. Compassion fatigue and burnout: the role of Balint groups. Aust Fam Physician 2005;34:497-8.

46. Haas JS. Physician discontent: a barometer of change and need for intervention. J Gen Intern Med 2001;16:496-7.

47. Rittenhouse DR, Mertz E, Keane D, Grumbach K. No exit: an evaluation of measures of physician attrition. Health Serv Res 2004;39:1571-88.

48. Rabow MW, McPhee SJ. Doctoring to heal: fostering well-being among physicians through personal reflection. West J Med 2001;174:66-9.

49. Remen RN. Recapturing the soul of medicine: physicians need to reclaim meaning in their working lives. West J Med 2001;174:4-5.

50. Roter DL, Hall JA, Aoki Y. Physician gender effects in medical communication: a meta-analytic review. JAMA 2002;288:756-64. 